\title{
Dynamic shear response and evolution mechanisms of adiabatic shear band in an ultrafine-grained austenite-ferrite duplex steel
}

\author{
Fuping Yuan*, Xiangde Bian, Ping Jiang, Muxing Yang, Xiaolei Wu \\ State Key Laboratory of Nonlinear Mechanics, Institute of Mechanics, Chinese Academy of Science, No. 15, North 4th Ring, West Road, Beijing 100190, China
}

\section{A R T I C L E I N F O}

\section{Article history:}

Received 4 April 2015

Received in revised form 3 June 2015

Available online 12 June 2015

\section{Keywords:}

Adiabatic shear band

Dynamic properties

TRIP

Hat-shaped specimen

Inverse transformation

\begin{abstract}
A B S T R A C T
The dynamic properties of an intercritically annealed 0.2C5Mn steel with ultrafine-grained austenite-ferrite duplex structure were studied under dynamic shear loading. The formation and evolution mechanisms of adiabatic shear band in this steel were then investigated using interrupted experiments at five different shear displacements and the subsequent microstructure observations. The dynamic shear plastic deformation of the $0.2 \mathrm{C} 5 \mathrm{Mn}$ steel was observed to have three stages: the strong linear hardening stage followed by the plateau stage, and then the strain softening stage associated with the evolution of adiabatic shear band. High impact shear toughness was found in this $0.2 \mathrm{C} 5 \mathrm{Mn}$ steel, which is due to the following two aspects: the strong linear strain hardening by martensite transformation at the first stage, and the suppressing for the formation of shear band by the continuous deformation in different phases through the proper stress and strain partitioning at the plateau stage. The evolution of adiabatic shear band was found to be a two-stage process, namely an initiation stage followed by a thickening stage. The shear band consists of two regions at the thickening stage: a core region and two transition layers. When the adjoining matrix is localized into the transition layers, the grains are refined along with increasing fraction of austenite phase by inverse transformation. However, when the transition layers are transformed into the core region, the fraction of austenite phase is decreased and almost disappeared due to martensite transformation again. These interesting observations in the core region and the transition layers should be attributed to the competitions of the microstructure evolutions associated with the non-uniformly distributed shear deformation and the inhomogeneous adiabatic temperature rise in the different region of shear band. The $0.2 \mathrm{C} 5 \mathrm{Mn}$ TRIP steel reported here can be considered as an excellent candidate for energy absorbers in the automotive industry.
\end{abstract}

(c) 2015 Elsevier Ltd. All rights reserved.

\section{Introduction}

The introduction of new types of steels in the automotive industry, such as transformation-induced-plasticity (TRIP) steels with metastable austenite and twinning-induced-plasticity (TWIP) steels with stable austenite, has been driven by the requirements to obtain

\footnotetext{
* Corresponding author. Tel.: +86 108254 4409; fax: +86 1082543977.

E-mail address: fpyuan@Inm.imech.ac.cn (F. Yuan).
}

high strength, high ductility and high energy absorption in meeting the demands for both lightweight and safety (Fischer et al., 2000; Jacques, 2004; Grässel et al., 2000; Frommeyer et al., 2003). A new type of TRIP steel with both high strength and excellent ductility has been developed by increasing the volume fraction of retained austenite and refining the grain size into the submicron region through intercritical annealing of $5 \mathrm{wt} . \%$ Mn steel (Miller, 1972; Niikura and Morris, 1980; Han et al., 2009; Shi et al., 2010a; Luo et al., 2011). Formation of the austenite 
phase during intercritical annealing, the strain-hardening behaviors and the mechanical stability of individual retained austenite grains of such 5Mn TRIP steels have been reported recently (Shi et al., 2010a; Luo et al., 2011; He et al., 2013).

It is known that both TRIP effect and grain size refinement contribute to the increase of strength in steels (Miller, 1972; Niikura and Morris, 1980; Valiev and Langdon, 2006; Zhilyaev and Langdon, 2008; Meyers et al., 2006; Dao et al., 2007). The grain size was found to have a strong effect on the transformation behavior of austenitic grains, and two contradictory conclusions could be found on this grain size effect in the previous research (Somani et al., 2009; Huang et al., 2011; Iwamoto and Tsuta, 2000; Shi et al., 2010b). Somani et al. (2009) and Huang et al. (2011) reported that martensite transformation could be enhanced significantly by ultra-fined austenite grains in $301 \mathrm{LN}$ stainless steel, which was contrary to the common observations that smaller austenite grains are more stable against transformation (Iwamoto and Tsuta, 2000; Shi et al., 2010b). Other factors, such as strain rate, temperature and stress triaxiality, were also found to have strong influences on TRIP effect: (i) at the low strain rate range $(<1 / s)$, TRIP effect happens at earlier strain for higher strain rate, while the maximum volume fraction of martensite decreases with increasing strain rate (Das and Tarafder, 2009; Lee et al., 2014; Prüger et al., 2014; Zaera et al., 2014); (ii) TRIP effect is suppressed with increasing temperature at the low temperature range (77-332 K) (Prüger et al., 2014; Zaera et al., 2014; Lebedev and Kosarchuk, 2000); (iii) increasing stress triaxiality intensifies TRIP effect (Lebedev and Kosarchuk, 2000; Jacques et al., 2007).

An important point of interest and concern for TRIP steels in automotive industry is the high strain rate $\left(10^{2} / \mathrm{s}\right.$ and above) behaviors as crash relevant structures (Prüger et al., 2014). At high strain rates, the generated heat cannot be dissipated to the environment which leads to a temperature rise in the material. So the high strain rate also has a high impact on the temperature dependent driving force for phase transformation. However, the influences of the ultra-high strain rate and the corresponding strain induced adiabatic temperature rise on TRIP effects are still unclear. Moreover, most energy absorbers require materials that are (i) capable of keeping a high value of the stress upon dynamic deformation, and (ii) able to show a large value of strain at failure $\varepsilon_{f}$. The second requirement is strongly dependent on the onset of strain localization which triggers material failure (Meyer and Manwaring, 1986; Meyers et al., 1994; Subhash et al., 1997; Jia et al., 2003; Wei et al., 2004; Xue et al., 2005; Bronkhorst et al., 2006; Wei et al., 2006a,b; Mishra et al., 2008; Yang et al., 2011; Yuan et al., 2012; Zaera et al., 2014). So the purpose of this paper is to investigate the mechanical properties for the 5Mn TRIP steel with ultra-fined grains (Shi et al., 2010a; Luo et al., 2011; He et al., 2013) under dynamic shear loading at high strain rate. The focus will be on the high strain rate deformation and temperature rise effects on transformation behaviors and how they affect the evolution of strain localization and the overall mechanical performance. In this regard, hat-shaped specimen set-ups in
Hopkinson bar experiments were used to study the dynamic shear deformation behaviors for the 5Mn TRIP steel by controlling the dynamic shear displacements in the present study.

\section{Experimental procedures}

The TRIP steel used in the present study, with a nominal composition of 0.2 wt.\% C and 5 wt.\% Mn, was first melted in a high-frequency induction furnace under a vacuum and then cast into a $50 \mathrm{~kg}$ ingot (Shi et al., 2010a). The ingots were then homogenized at $1250{ }^{\circ} \mathrm{C}$ for $2 \mathrm{~h}$, and forged between $850^{\circ} \mathrm{C}$ and $1200^{\circ} \mathrm{C}$ into rods with diameters of $16 \mathrm{~mm}$, finally cooled in the furnace to room temperature (RT). The forged rods were austenized at $750{ }^{\circ} \mathrm{C}$ for half an hour and quenched in oil, and then intercritically annealed at $650{ }^{\circ} \mathrm{C}$ for $6 \mathrm{~h}$ in a box furnace under a vacuum and finally air cooled to RT. The heating rate was estimated to be around $40-60^{\circ} \mathrm{C} / \mathrm{s}$ during the intercritical annealing. The microstructure after intercritical annealing was examined by optical microscope (OM), electron backscattered diffraction (EBSD) and transmission electron microscope (TEM). The annealed sample surfaces for EBSD were first polished to 2000 grit and finally polished with $0.25 \mu \mathrm{m}$ diamond paste and $0.05 \mu \mathrm{m} \mathrm{SiO}{ }_{2}$ aqueous solution, and then were electro-polished with $10 \%$ Nital at $20 \mathrm{~V}$ voltage and $-20^{\circ} \mathrm{C}$ to reveal the microstructure. Disks for TEM were cut with a thickness of $300 \mu \mathrm{m}$ and polished down to $50 \mu \mathrm{m}$ using 2000 grid SiC papers. Final thinning to electron transparency was achieved by ion milling.

All samples for mechanical testing were machined from the intercritically annealed rods by wire saw with loading direction parallel to the axis of rods. The hat-shaped specimen set-up for Hopkinson bar experiment is shown in Fig. 1(a), and the geometry and dimensions of the hat-shaped specimens are given in Fig. 1(b). The hat-shaped design has been widely used to study adiabatic shear band (ASB) in various metals (Meyer and Manwaring, 1986; Meyers et al., 1994; Xue et al., 2005; Bronkhorst et al., 2006; Mishra et al., 2008; Yang et al. 2011; Yuan et al., 2012). The hat shape is designed to concentrate shear deformation in a narrow zone facilitating the formation of a shear band (Meyer and Manwaring, 1986). Details of the Hopkinson-bar technique can be found elsewhere (Subhash et al., 1997; Song et al., 2009; Sunny et al., 2009). According to the one-dimensional elastic stress wave theory, the shear stress, the shear displacement, the nominal shear strain and the nominal shear strain rate can be calculated as:

$$
\begin{aligned}
& \tau_{s}=E\left(\frac{A}{A_{s}}\right) \varepsilon_{T} \\
& U_{s}=2 C_{0} \int_{0}^{t} \varepsilon_{R} d \tau \\
& \gamma_{s}=U_{s} / t_{s} \\
& \dot{\gamma}_{s}=\frac{2 C_{0}}{t_{s}} \varepsilon_{R}
\end{aligned}
$$


(a)

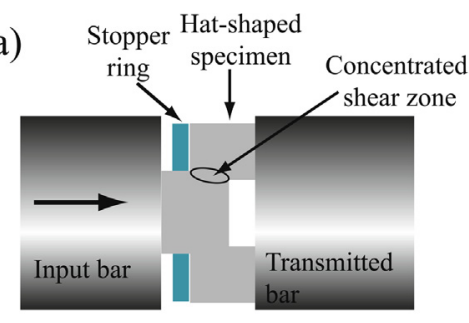

(b)

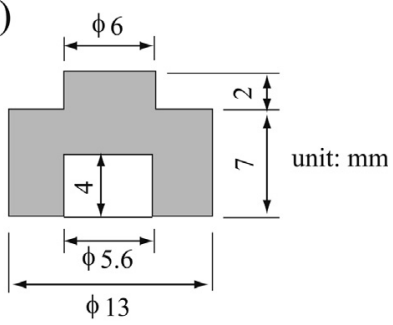

(c)

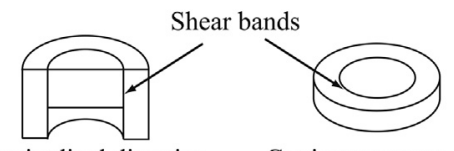

Cut in longitudinal direction for OM, SEM, EBSD and hardness

Cut in transverse direction for TEM

Fig. 1. (a) Hat-shaped specimen set-up in Hopkinson bar experiment; (b) Geometry and dimensions of hat-shaped specimen; (c) Longitudinal and transverse cuts for microstructure observations.

where $\varepsilon_{T}$ and $\varepsilon_{R}$ are the transmitted and reflected strain pulses, which can be measured by the strain gages attached to the input and output bars, respectively; $C_{0}, E$ and $A$ are the longitudinal elastic wave velocity, Young's modulus and the cross-sectional area of the loading bars, respectively; $t_{s}$ and $A_{s}$ are the thickness and the area of the concentrated shear zone, respectively.

Following impact, the hat-shaped specimens were sectioned in half along the impact axis (longitudinal direction as shown in Fig. 1(c)). The half sections were then polished to 2000 grit and final polished with $0.25 \mu \mathrm{m}$ diamond paste and $0.05 \mu \mathrm{m} \mathrm{SiO}_{2}$ aqueous solution. This was followed by etching with $1.5 \mathrm{~g} \mathrm{CuCl}_{2}+33 \mathrm{ml} \mathrm{HCl}+33 \mathrm{ml}$ $\mathrm{H}_{2} \mathrm{O}$. The etched half sections were then examined by $\mathrm{OM}$ and SEM. Micro-hardness measurements were also made on these polished half sections using a Vickers diamond indenter at a load of $5 \mathrm{~g}$ for $10 \mathrm{~s}$ dwell time. The light load is especially compatible with measurements within ASB which have widths ranging from roughly 12 to $43 \mu \mathrm{m}$. Ten groups of measurements traversing the ASB were made, and the average value was taken for reducing the physical error. The polished half sections were electro-polished with $10 \%$ Nital at $20 \mathrm{~V}$ voltage and $-20^{\circ} \mathrm{C}$ to reveal the microstructure for EBSD. The spatial resolution of EBSD were significantly improved through the use of a field emission gun and low accelerating voltage, and appropriate sample preparation, making it possible to successfully explore the microstructure evolution in the shear band (Chen et al., 2011a,b; Sun et al., 2014). Samples for TEM observations near the shear band were cut with a thickness of $300 \mu \mathrm{m}$ along the transverse direction (as shown in Fig. 1(c)), and then polished down to $50 \mu \mathrm{m}$ using 2000 grid SiC papers. To assure specific locations, the surfaces were etched with $1.5 \mathrm{~g} \mathrm{CuCl}_{2}+33 \mathrm{ml}$ $\mathrm{HCl}+33 \mathrm{ml} \mathrm{H}_{2} \mathrm{O}$ and examined by optical microscope. This is very important in locating regions within and/or adjacent to ASB. Then electron transparency was achieved at regions around the ASB by ion milling, and this ensures that the area within the shear band could be examined under TEM.

\section{Experimental results}

Intercritical annealing of Mn-bearing steel was demonstrated to be a method capable of fabricating an ultrafine-grained austenite-ferrite duplex steel by austenite-reverted transformation (ART-annealing) (Shi et al., 2010a; Luo et al., 2011; He et al., 2013). The ultrafine-grained austenite-ferrite duplex structure developed by ART annealing is shown in Fig. 2 by OM, EBSD and TEM. In Fig. 2(b), the austenite laths are represented by relatively dark color while ferrite laths are discerned by relative light color, and the average grain size estimated by EBSD micrograph is about $500 \mathrm{~nm}$. After ART-annealing, both austenite and ferrite show slightly band structure, and the average thickness of both austenite and ferrite laths is about $300 \mathrm{~nm}$ based on TEM observations, as shown in Fig. 2(c). There is an obvious discrepancy for the grain sizes estimated from EBSD and TEM, which is because that EBSD micrograph was observed from longitudinal direction while TEM micrograph was observed from transverse direction, and some features are hard to be discerned by EBSD. The corresponding selected area diffraction (SAD) patterns for both austenite and ferrite are also shown in the insets of Fig. 2(c). The EBSD measurements also reveal that the austenite fraction is about $27 \%$ after ART-annealing.

A series of experiments using Hopkinson-bar technique were conducted to investigate the formation and evolution mechanisms of ASB in the intercritically annealed $0.2 \mathrm{C} 5 \mathrm{Mn}$ TRIP steel. By means of adjusting the thickness of the stopper ring, as shown in Fig. 1, the dynamic shear process was interrupted at five different shear displacements and the microstructures were "frozen" at these stages for subsequent observations. Fig. 3(a) shows the shear stress as a function of the shear displacement for the tests with various interrupted displacements. We did at least two experiments for each interrupted displacement, and the insert of Fig. 3(a) shows very good reproducibility. The nominal shear strain in the hat-shaped specimen can be estimated by dividing the shear displacement by the thickness of 

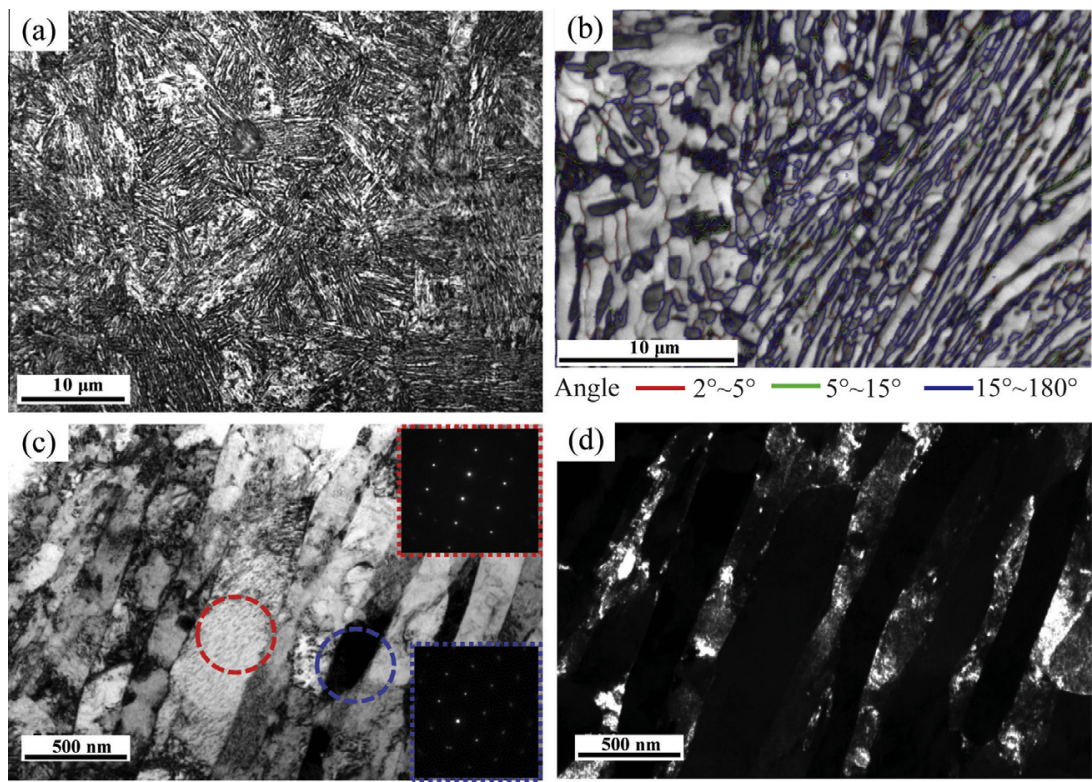

Fig. 2. Microstructures of the $0.2 \mathrm{C} 5 \mathrm{Mn}$ steel with the ultrafine-grained austenite-ferrite duplex structure after intercritically annealing: (a) Optical micrograph; (b) EBSD micrograph with misorientation angles; (c) Bright-field TEM micrograph; (d) Dark-field TEM micrograph.
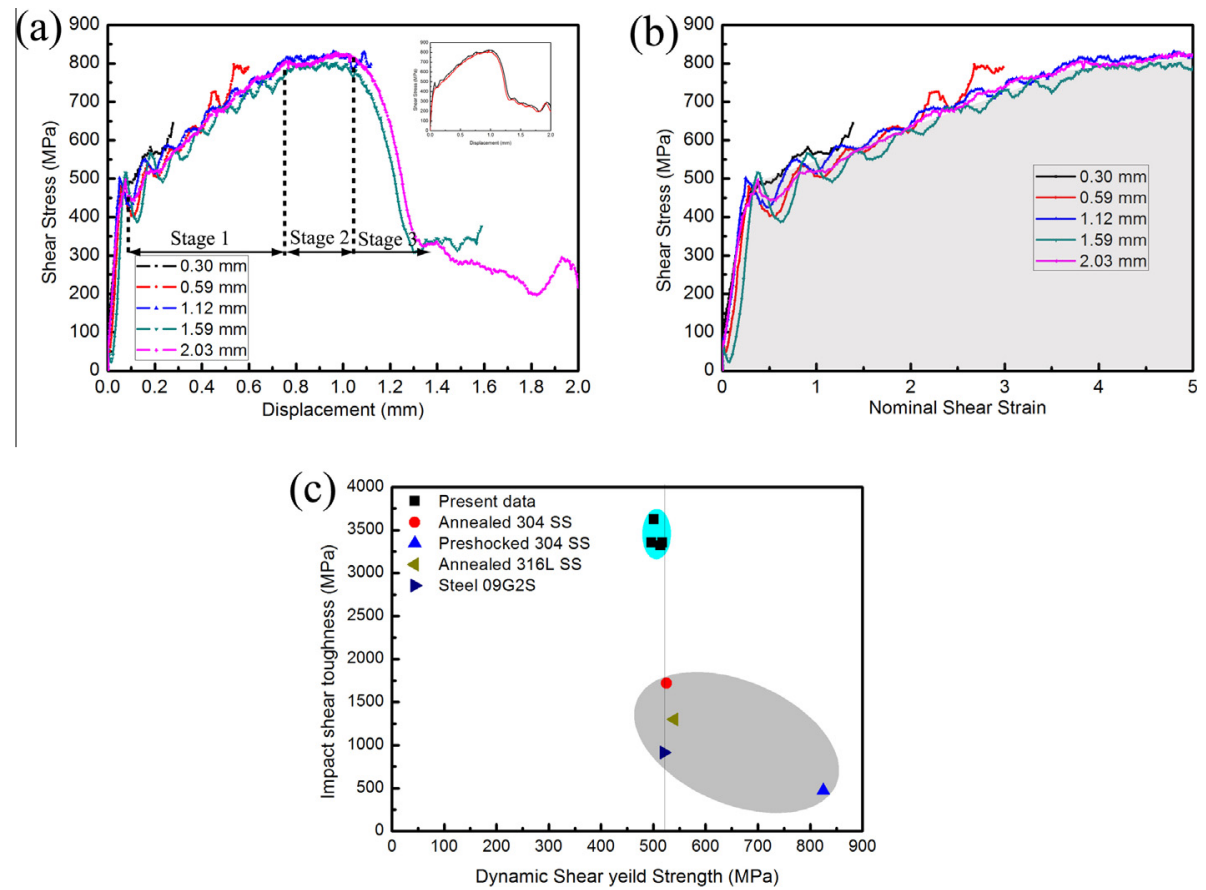

Fig. 3. (a) Shear stress vs. shear displacement curves of the intercritically annealed 0.2C5Mn steel after various interrupted displacements; (b) Shear stress vs. nominal shear strain curves of the intercritically annealed $0.2 \mathrm{C} 5 \mathrm{Mn}$ steel after various interrupted displacements; (c) Impact shear toughness vs. dynamic shear yield strength for various steels.

the concentrated shear zone when assuming homogeneous deformation in the concentrated shear zone before the formation of ASB. Fig. 3(b) shows the shear stress vs. the nominal shear strain curves, and the dynamic shear yield strength is estimated to be $\sim 500 \mathrm{MPa}$. These curves indicate that the intercritically annealed $0.2 \mathrm{C} 5 \mathrm{Mn}$ TRIP steel has a strong strain-hardening response after elastic deformation, and the whole plastic response under the imposed dynamic shear loading can be divided into three stages. At the first stage (with shear displacements below 
$0.75 \mathrm{~mm}$ ), the shear stress increases and maintains a continuous response of strong linear hardening. And then at the second stage, the rise rate of strain-hardening slows down, and finally reaches and keeps at a plateau until the point with the shear displacement of approximately $1.0 \mathrm{~mm}$. This point reflects a starting point after which strain softening begins to dominate with further deformation. At the third stage, the shear stress drops abruptly at shear displacements between 1.0 and $1.33 \mathrm{~mm}$, and then decreases slowly with further shear deformation. In terms of the maximum stress criterion for instability that has been widely accepted in the analysis of adiabatic shear deformation (Meyers et al., 1994; Xue et al., 2005; Mishra et al., 2008; Yuan et al., 2012), the peak point in the shear stress-shear displacement curves is generally considered as the initiation point of the instability, after which strain localization, such as ASB, begins to form and evolve. Thus, the experienced homogeneous shear strain is estimated to be about 5.0 for the intercritically annealed $0.2 \mathrm{C} 5 \mathrm{Mn}$ TRIP steel. The shaded area in the Fig. 3(b) can be considered as the impact shear toughness under dynamic shear loading using hat-shaped specimen before strain localization.

Driven by the need to retain impact toughness while reaping the strengthening benefits from the ultrafine-grained austenite-ferrite duplex structure, the intercritically annealed $0.2 \mathrm{C} 5 \mathrm{Mn}$ TRIP steel reported here can be considered as an excellent candidate to energy absorbers in the automotive industry, which is illustrated in Fig. 3(c). In Fig. 3(c), the impact shear toughness under dynamic shear loading using hat-shaped specimen is plotted against the dynamic shear yield strength for our data, along with other data points (with similar hat-shaped specimen design) for various steels (Xue et al., 2005; Bronkhorst et al., 2006; Pushkov et al., 2009). As indicated, the intercritically annealed $0.2 \mathrm{C} 5 \mathrm{Mn}$ TRIP steel has 2 times or even higher of impact shear toughness at the similar dynamic shear strength level when compared to the other steels. For example, the coarse-grained 304 and 316L stainless steels have the dynamic shear yield strength of 525 and $540 \mathrm{MPa}$ respectively, with the impact shear toughness of 1720 and $1300 \mathrm{MPa}$ respectively (Xue et al., 2005; Bronkhorst et al., 2006). While the impact shear toughness of the $0.2 \mathrm{C} 5 \mathrm{Mn}$ steel is at the range of $3300-3600 \mathrm{MPa}$ (2 times or even higher when compared to the coarse -grained 304 and 316L stainless steels), and the dynamic shear yield strength (496-517 MPa) is similar to those of the coarse-grained 304 and 316L stainless steels. The analysis for this high impact toughness will be presented in the discussion section.

The main advantage of the hat-shaped specimen test with controlled shear displacements is that the mechanical response can be correlated quantitatively with the microstructure evolutions. Fig. 4(a)-(d) show the corresponding OM pictures of half cross-section at four different interrupted displacements (0.59, 1.12, 1.59 and $2.03 \mathrm{~mm}$ ). In these figures, all bottom ends are the base ends and all upper ends are the hat ends. Fig. 5(a)-(c) show the corresponding SEM observations of the shear bands at the last three interrupted displacements $(1.12,1.59$ and $2.03 \mathrm{~mm}$ ). As indicated in the stress-displacement curves, the deformation at the shear displacement of $0.59 \mathrm{~mm}$ does not localize. The OM (Fig. 4(a)) also approves that the shear deformation is not enough to form a shear band at the shear displacement of $0.59 \mathrm{~mm}$. For the predicted maximum stress criterion, the stage at the stress peak is assumed to be the onset of nucleation of shear localization, with a critical shear displacement of around $1.0 \mathrm{~mm}$ and a critical shear strain around 5 . This also can be illustrated in Fig. 4(b) in which a thin localized band is observed when the shear displacement is slightly over the peak point (1.12 mm).

As shear displacement is further increased, the evolution of the shear band is found to be a two-stage process, namely an initiation stage (Figs. 4(b) and 5(a)) followed by a thickening stage (Figs. $4(\mathrm{c})-(\mathrm{d})$ and $5(\mathrm{~b})-(\mathrm{c})$ ). This evolution process of shear band is very similar to that observed for the $\alpha$-hcp titanium (Meyers et al., 1994) and that observed for ultrafine-grained Fe reported in our previous research (Yuan et al., 2012). The shear band consists of two regions at the thickening stage (Fig. 5(b) and (c)): a core region and two transition layers. Increasing in shear deformation leads to thickening of shear bands, which is composed of thickening of the core region by transforming the transition layers into the core region, and outward movement of the transition layers by deforming the adjoining matrix. As shown in Fig. 5(a), the initial shear band has similar features to the transition layers of the thickening stages (Fig. 5(b) and (c)), and has a width of $12 \mu \mathrm{m}$. In the thickening stage, ASB width is increased from 12 to $43 \mu \mathrm{m}$ when the shear displacement is increased from 1.12 to $2.03 \mathrm{~mm}$. Similar trend on the evolution of the ASB width with increasing shear displacement was also found in the $\alpha$-hcp titanium (Meyers et al., 1994) and the ultrafine-grained Fe (Yuan et al., 2012). As shown in Fig. 4(b)-(d), once ASB is formed, micro-voids and micro-cracks in the ASB also coalesce into observable cracks which propagate along the ASB from the base/upper ends to the center area when the shear displacement is increased. The average crack length is increased from 0.46 to $1.5 \mathrm{~mm}$ when the shear displacement is increased from 1.12 to $2.03 \mathrm{~mm}$. It is clear that these cracks are the result of the corner point motion (either the upper end or the base end), and the increased shear displacement leads these cracks to propagate at both ends. The high temperature generated during the shear deformation within ASB is also facilitated the propagation of cracks in the materials.

Grain orientations adjacent to the ASB were characterized using EBSD. Fig. 6 shows the EBSD orientation maps at three different interrupted displacements (undeformed, 1.12 and $2.03 \mathrm{~mm}$ ). The orientation maps presented here use the inverse pole figure coloring scheme relative to the direction of cross section. The color codes follow the inserted triangle in Fig. 6, in which grains having [001], [101] and [111] directions parallel to the direction of cross section are in red, green and blue, respectively. As shown, the grains in the shear band (both in the transition layers and in the center region) are relatively equiaxed and clearly different from the band structure of the matrix. The misorientation angles are also observed to be much larger in the shear band when compared to the surrounding matrix. 


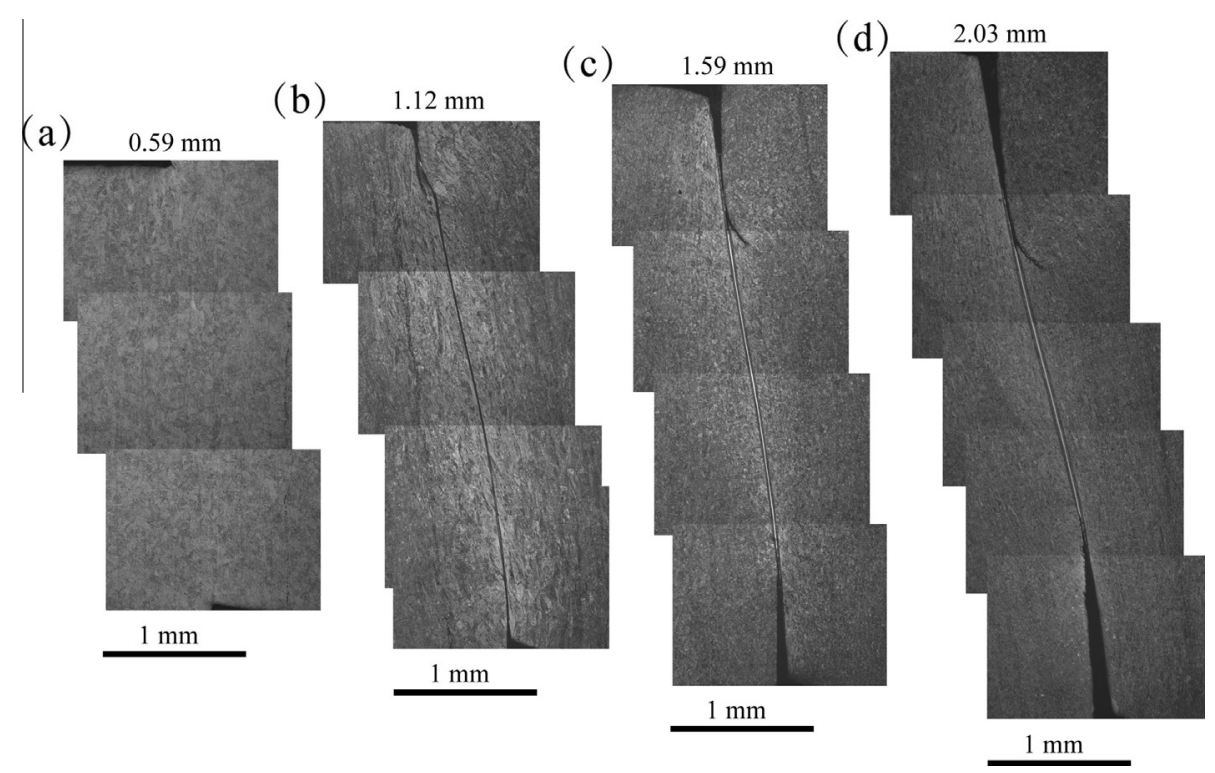

Fig. 4. Optical micrographs of half cross section observed at four different interrupted displacements (a)-(d).
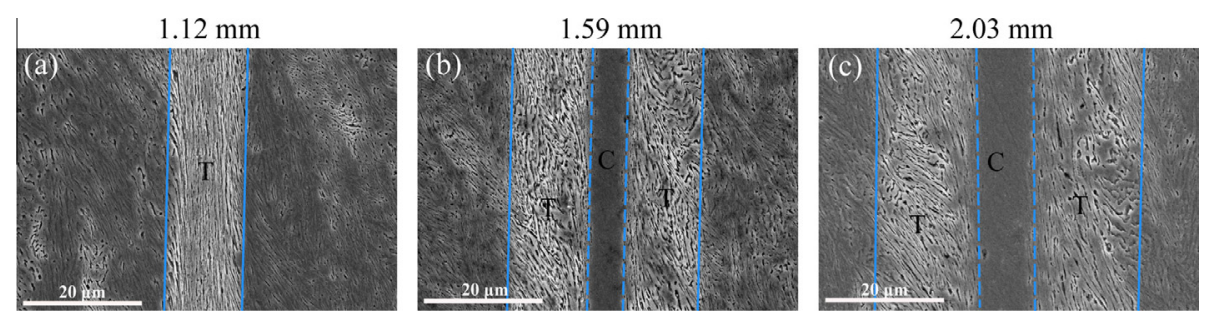

Fig. 5. SEM micrographs of the shear band as observed at three different interrupted displacements (a)-(c). The transition layer is marked as " $T$ " and the center region is marked as " $\mathrm{C}$ ".
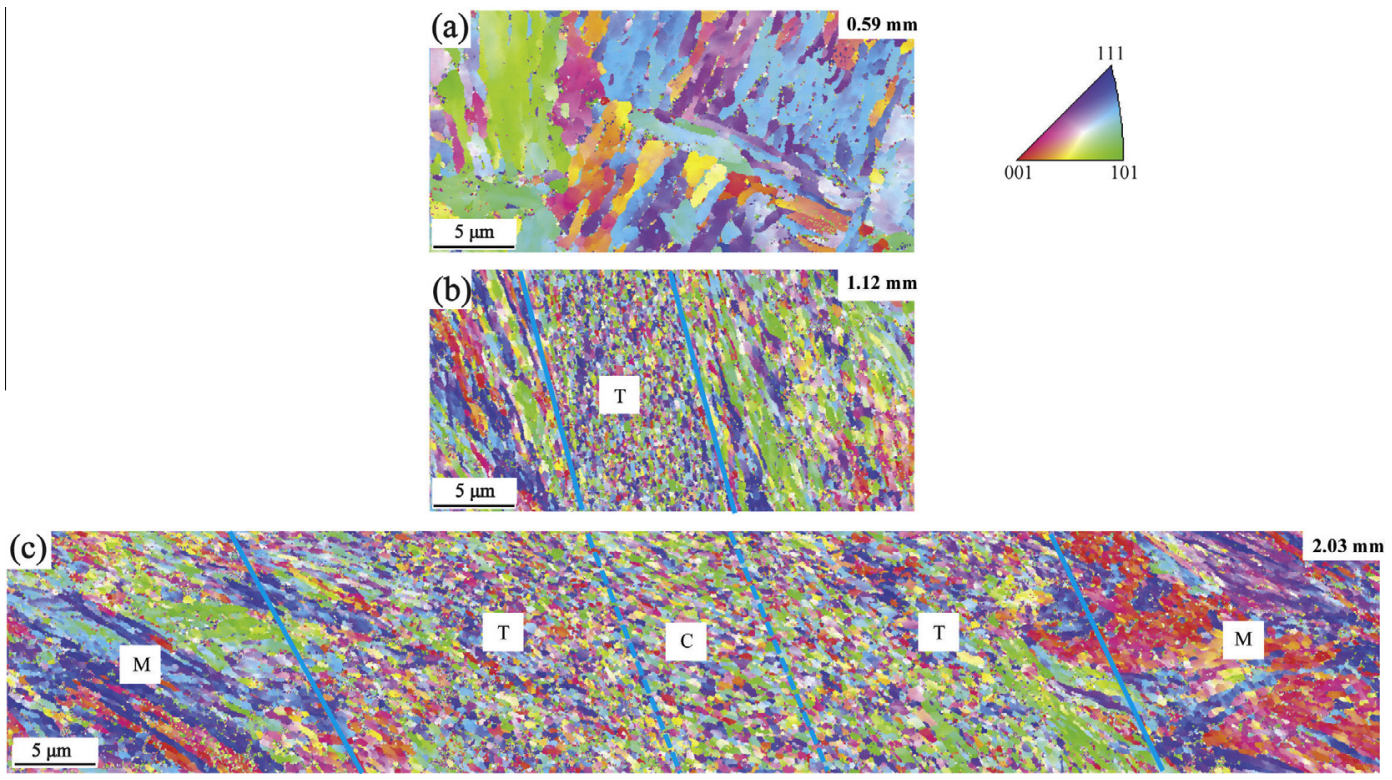

Fig. 6. The orientation maps by EBSD at three different interrupted displacements (a) un-deformed sample; (b) $1.12 \mathrm{~mm}$; (c) $2.03 \mathrm{~mm}$. 
Fig. 7(a) shows the EBSD grain distribution map at the shear displacement of $2.03 \mathrm{~mm}$. The corresponding amplified figures for the matrix, the transition layer and the center region are shown in Fig. 7(b)-(d), respectively. In these figures, different colors represent different grains and white areas are non-indexable positions due to poor Kikuchi pattern quality. Fig. 8 shows the TEM micrograph of microstructure for the center region at the shear displacement of $2.03 \mathrm{~mm}$. Based on TEM observations, the grain size is observed to be refined to $150 \mathrm{~nm}$ from the initial $300 \mathrm{~nm}$ of the un-deformed state (Fig. 2(c)). As indicated in Fig. 7, the band structure in the matrix is transformed into equiaxed grains in the shear band due to the severe shear deformation. The grains in the transition layer are much refined when compared to the grains in the surrounding matrix, while the grains in the center region is slightly larger than those in the transition layers. These observations may be due to the competition between the shear deformation induced grain refinement and the high temperature rise induced grain growth.

Fig. 9 shows the EBSD phase distributions at four different interrupted displacements (un-deformed, 0.59, 1.12 and $2.03 \mathrm{~mm}$ ). The austenite phase is shown by red color, while ferrite and martensite phases are shown by green color. Before the formation of ASB, the fraction of austenite phase is reduced by homogeneous shear deformation due to the TRIP effect (austenite-to-martensite transformation), which gives the linear strain hardening as shown in Fig. 3(b). However, the fraction of austenite phase in the initial shear band (with features of the transition layer) is increased when compared to the surrounding matrix due to the inverse transformation (martensite-to-austenite transformation). In the final stage of ASB (at the shear displacement of $2.03 \mathrm{~mm}$ ), the center region has the smallest fraction of austenite phase (much smaller than the transition layer and even smaller than the surrounding matrix) due to the martensite transformation again. The interesting distribution of austenite phase observed in the matrix, the transition layers and the center region are actually due to the competition between shear deformation induced

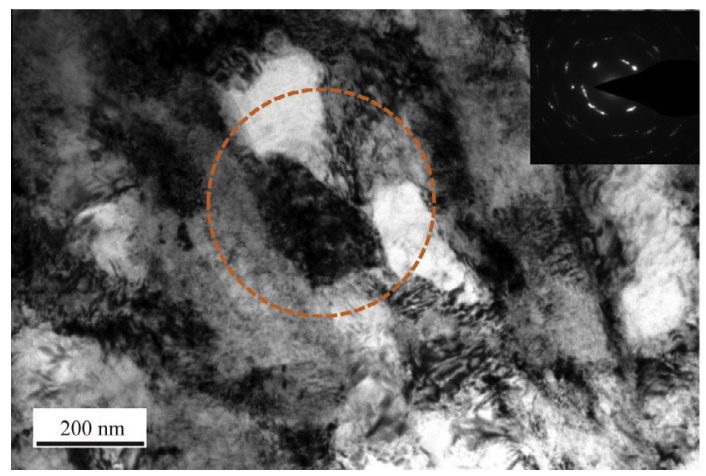

Fig. 8. TEM micrograph of microstructure for the center region at the shear displacement of $2.03 \mathrm{~mm}$.

martensite transformation and the inverse transformation induced by the high temperature rise and the rapid quench after deformation. The evolutions of the austenite phase fraction and the grain size based on EBSD with increasing shear displacement for the matrix, the transition layers and the center region are summarized in Table 1.

Fig. 10 shows Vickers micro-hardness distributions traversing the ASB at four different interrupted displacements $(0.59,1.12,1.59$ and $2.03 \mathrm{~mm})$. The corresponding SEM figures are also inserted at the same length scale for the last three interrupted displacements to clearly show the positions of the core region and the transition layers. As indicated in Fig. 4(a), $0.59 \mathrm{~mm}$ shear displacement is not enough to form a shear band, and this can also be identified by the micro-hardness distribution in Fig. 10(a), in which no obvious peak is observed. However, the homogeneous shear deformation is still accompanied by increasing in micro-hardness of the matrix when compared to the un-deformed stage due to the martensite transformation. As shown in the Fig. 10(b), an obvious peak is observed for the initial shear band at the shear displacement of $1.12 \mathrm{~mm}$. In the
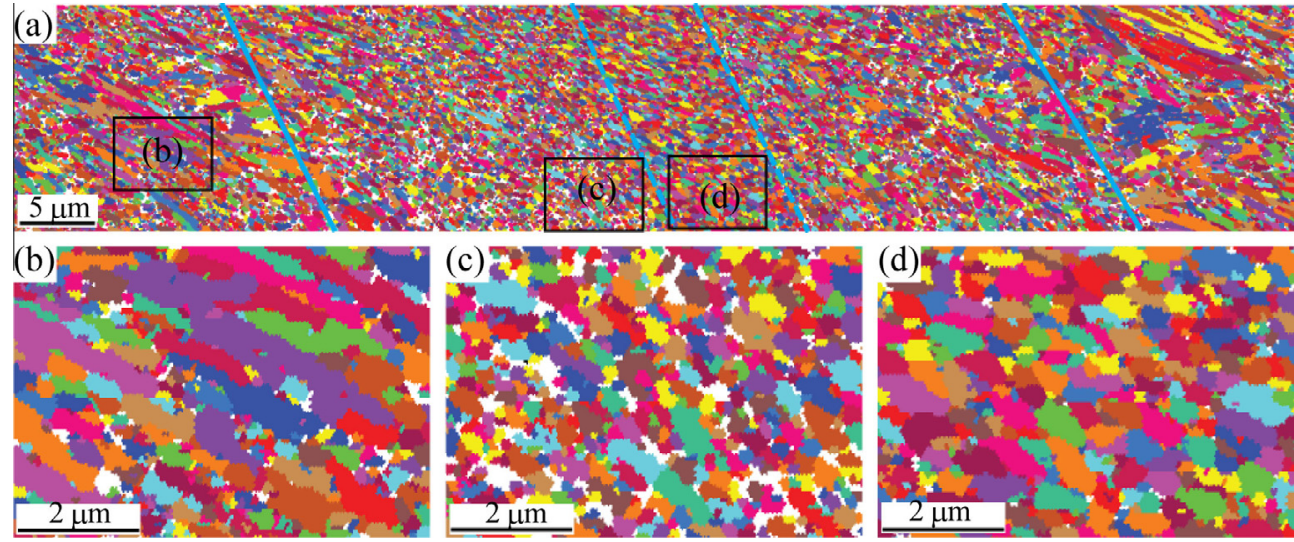

Fig. 7. The grain distribution maps by EBSD at the shear displacement of $2.03 \mathrm{~mm}$. Fig. 7(b)-(d) are the corresponding amplified figures for the marked rectangle areas (representing the matrix, the transition layer and the center region) in Fig. 7(a). 

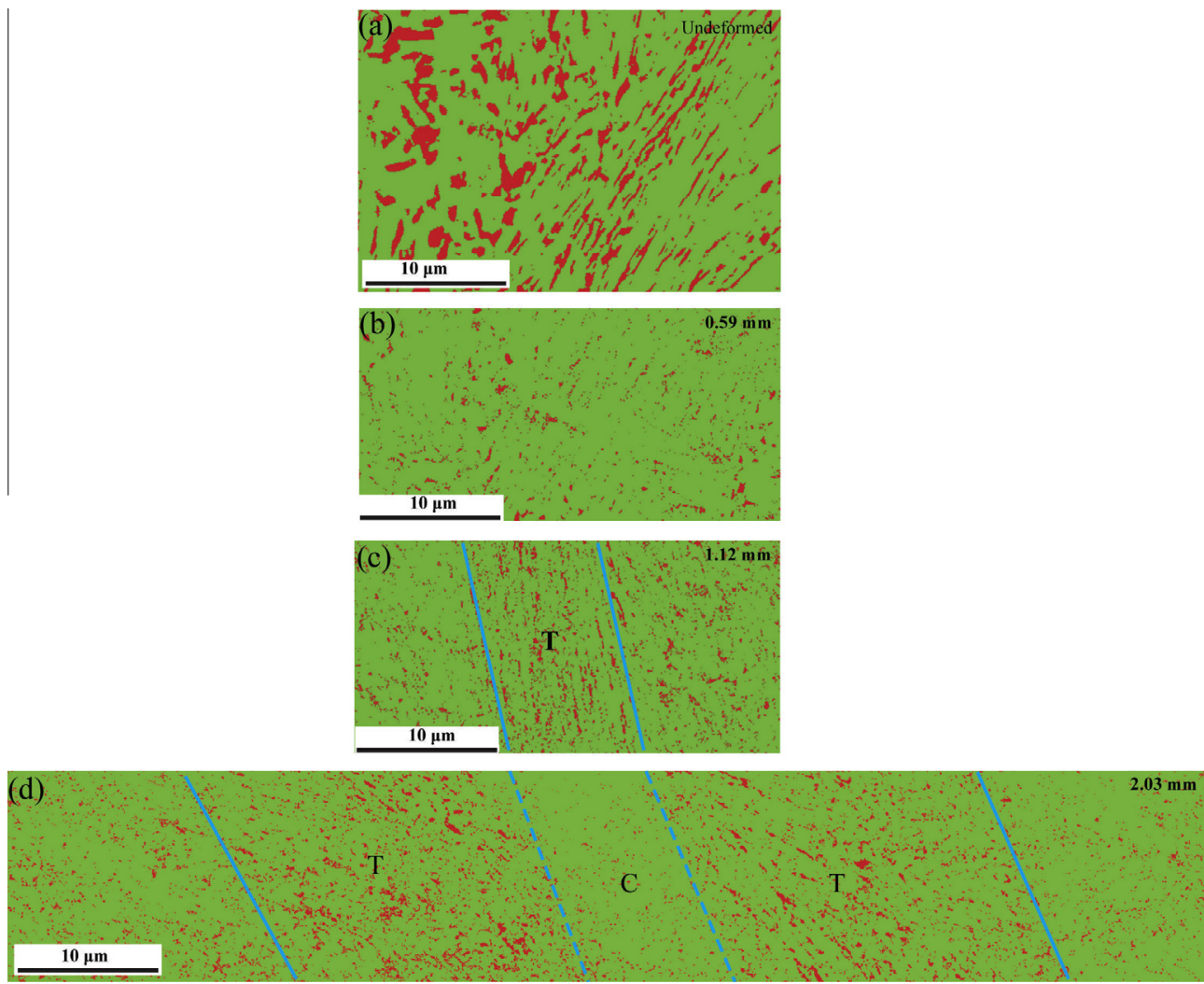

Fig. 9. The phase distribution maps by EBSD at four different interrupted displacements (a) un-deformed sample; (b) $0.59 \mathrm{~mm}$; (c) $1.12 \mathrm{~mm}$; (d) $2.03 \mathrm{~mm}$. The red area is for austenite phase and the rest area is for ferrite and martensite phases. (For interpretation of the references to color in this figure legend, the reader is referred to the web version of this article.)

Table 1

The austenite phase fraction and grain size measured for different areas in the intercritically annealed $0.2 \mathrm{C} 5 \mathrm{Mn}$ steel.

\begin{tabular}{|c|c|c|c|c|c|c|}
\hline \multirow[t]{2}{*}{ Displacement (mm) } & \multicolumn{3}{|c|}{ Austenite phase fraction (\%) } & \multicolumn{3}{|c|}{ Grain size $(\mathrm{nm})$} \\
\hline & Matrix & Transition & Center & Matrix & Transition & Center \\
\hline 0.0 & 27 & $\mathrm{~N} / \mathrm{A}$ & $\mathrm{N} / \mathrm{A}$ & 497 & $\mathrm{~N} / \mathrm{A}$ & $\mathrm{N} / \mathrm{A}$ \\
\hline 0.59 & 5 & N/A & $\mathrm{N} / \mathrm{A}$ & 403 & $\mathrm{~N} / \mathrm{A}$ & $\mathrm{N} / \mathrm{A}$ \\
\hline 1.12 & 5.4 & 13.5 & $\mathrm{~N} / \mathrm{A}$ & 263 & 190 & $\mathrm{~N} / \mathrm{A}$ \\
\hline 2.03 & 5.6 & 16.9 & 4.5 & 312 & 209 & 245 \\
\hline
\end{tabular}

thickening stages (Fig. 10(c) and (d)), the center region of ASB is found to have the highest micro-hardness, while the micro-hardness of the transition layers has the smallest value and is even lower than that of the surrounding matrix. The lowest fraction of austenite and the grain refinement compared to the matrix are the main reasons for the highest micro-hardness in the center region. While the smallest micro-hardness in the transition layers is due to the highest fraction of austenite due to the reverse transformation although the grains are much refined in the transition layers when compared to the surrounding matrix. All measurements mentioned earlier (such as width of ASB, average crack length, micro-hardness of matrix, transition layers and center region) are summarized in Table 2.

\section{Discussions}

Estimation of the shear strain and the shear strain rate within ASB is of importance to understand the microstructure evolution within ASB. Although it is very difficult to directly measure these quantities in the ASB, a theoretical analysis of estimating these quantities can be developed by measuring the interrupted shear displacement and the corresponding ASB width. In the analysis, three assumptions need to be made: (i) the stress peak is considered to be the starting point of strain localization (Xue et al., 2005; Mishra et al., 2008; Yuan et al., 2012); (ii) once ASB starts, the deformation is assumed to be completely carried by ASB, which will give an upper limit for estimations due to the minimal deformation still carrying by the area 


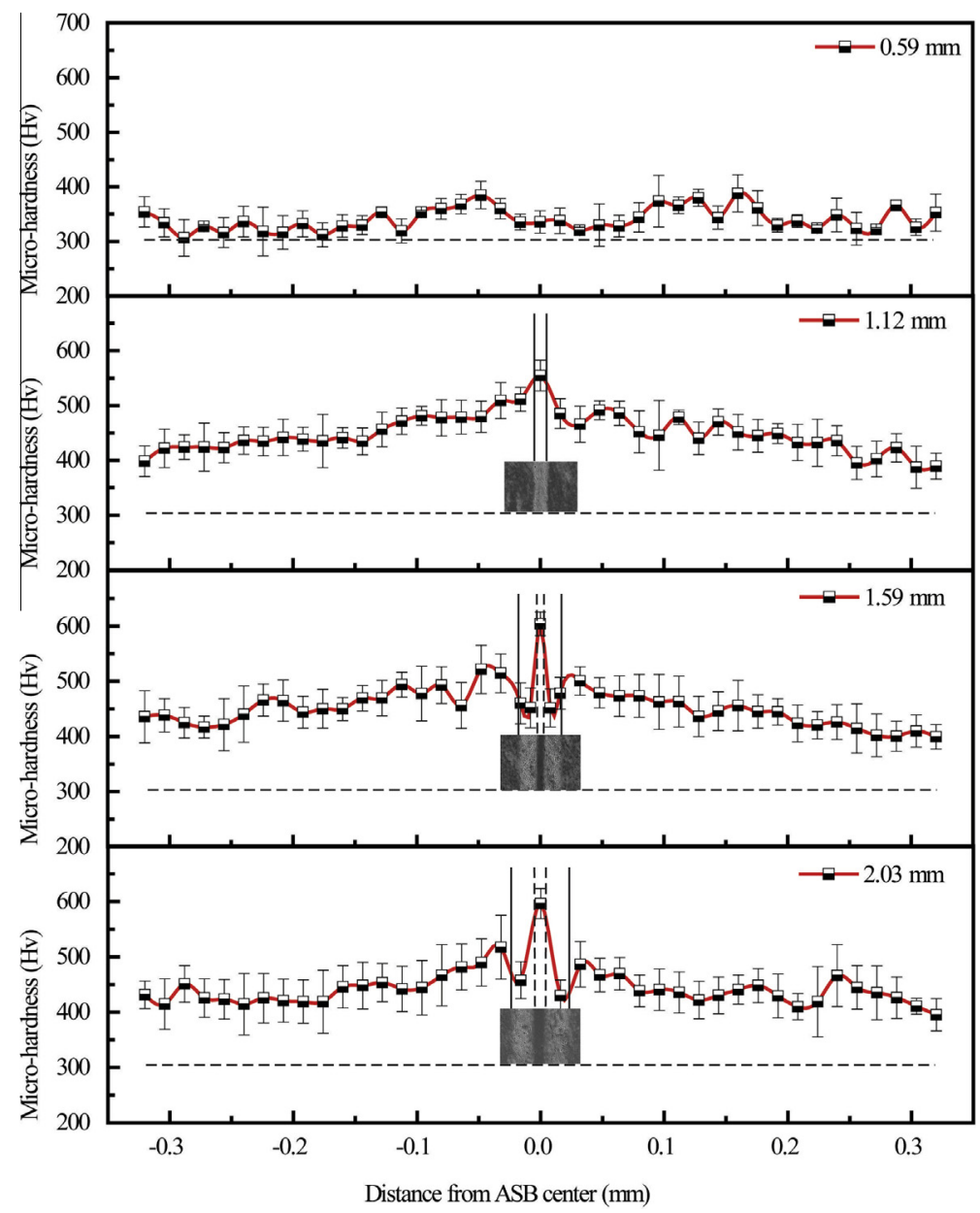

Fig. 10. Vickers micro-hardness distributions traversing the ASB at four different interrupted displacements (a)-(d). The initial hardness for un-deformed sample is also given by a dashed straight line.

Table 2

The average crack length, the ASB width and the micro-hardness measured for different areas in the intercritically annealed $0.2 \mathrm{C} 5 \mathrm{Mn}$ steel.

\begin{tabular}{|c|c|c|c|c|c|}
\hline \multirow{2}{*}{$\begin{array}{l}\text { Displacement } \\
(\mathrm{mm})\end{array}$} & \multirow{2}{*}{$\begin{array}{l}\text { Average } \\
\text { crack } \\
\text { length } \\
(\mathrm{mm})\end{array}$} & \multirow{2}{*}{$\begin{array}{l}\text { ASB } \\
\text { width } \\
(\mu \mathrm{m})\end{array}$} & \multicolumn{3}{|c|}{ Micro-hardness (Hv) } \\
\hline & & & Matrix & Transition & Center \\
\hline 0.59 & 0 & 0 & 341 & $\mathrm{~N} / \mathrm{A}$ & $\mathrm{N} / \mathrm{A}$ \\
\hline 1.12 & 0.46 & 12 & 498 & 554 & $\mathrm{~N} / \mathrm{A}$ \\
\hline 1.59 & 1.1 & 35 & 511 & 452 & 604 \\
\hline 2.03 & 1.5 & 45 & 502 & 444 & 596 \\
\hline
\end{tabular}

adjacent to the ASB; (iii) the ASB width at any shear displacement can be obtained by polynomial fitting based on least square method from three measured ASB widths at three interrupted shear displacements $(1.12,1.59$ and $2.03 \mathrm{~mm}$ ). The real-time shear strain rate can be estimated using the shear displacement increment at time interval of $\Delta t$ divided by the current ASB width. The detailed results for the shear strain and the shear strain rate distributions at various interrupted displacements are shown in Fig. 11(a) and (b). As indicated, the shear strain within
ASB is as high as order of tens, and the shear strain rate within ASB is as high as order of $10^{4}-10^{5}$. These calculations show that the shear deformation amplitude within the ASB are highly non-uniform, giving that the center region has much higher experienced shear strain. These highly non-uniform shear strain within ASB should also result in non-uniform plastic-strain-induced temperature rise. Thus, the interesting microstructure observations in the core region and the transition layers should be attributed to the competitions of the microstructure evolutions associated with the non-uniformly distributed shear deformation and the inhomogeneous adiabatic temperature rise in the different region of shear band.

Based on perturbation analysis of the uniform solutions to the governing equation of ASB, Bai and Dodd (1992) proposed the following equation for estimating $\delta$, the width of ASB:

$\delta \approx 2\left(\frac{k T}{\tau \dot{\gamma}}\right)^{1 / 2}$

where $k$ is the thermal conductivity (60 W/K.m), and $T, \tau$ and $\gamma$ are the temperature, the shear stress, and the shear 

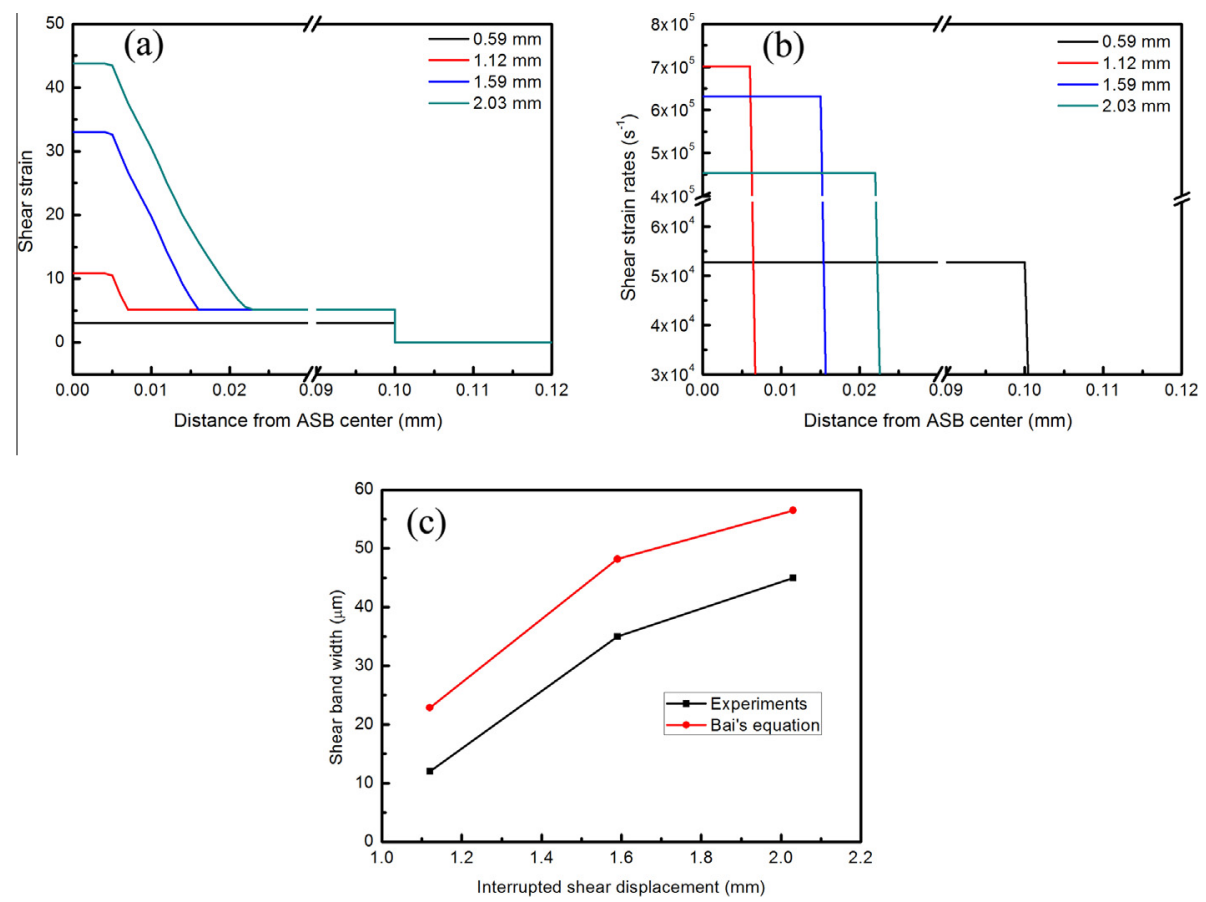

Fig. 11. (a) Shear strain distributions within ASB at various interrupted shear displacements. (b) Shear strain rate distributions within ASB at various interrupted shear displacements. (c) Shear band width as a functions of shear displacement obtained from experiments as compared to the prediction by Bai's equation (Bai and Dodd, 1992).

strain rate within the ASB. The shear stress and the shear strain rate at various interrupted shear displacements can be obtained from Figs. 3 and 11(b), respectively. The average temperature rise rate within ASB can be calculated assuming that $90 \%$ of plastic work induced by the shear strain increment at time interval of $\Delta t$ converts to heat under adiabatic condition, which also gives an upper limit since a small amount of heat can still be dissipated at such a short time. Once the shear strain, the shear strain rate and the temperature rise within ASB are obtained, the width of ASB can be estimated by theoretical analysis (Bai and Dodd, 1992). Fig. 11(c) shows the predictions from the above equation and the measured shear band widths from experiments at various interrupted shear displacements. Wright (2002) stated that the agreement of experimental results with Bai's equation is usually within a factor of 2. According to Wright's statement, there is a relatively well agreement between experimental results and Bai's equations. Both experimental results and Bai's equations predict an increase in shear band widths with increasing shear displacement, and the trend of experimental data parallels Bai's equations.

On examining the ASB features and microstructures implicit in Figs. 5-7 and 9, the evolutionary sequence occurred during the dynamic shear loading can be divided into the following four steps. (i) the initial microstructure begins with band structure of large grains and large fraction of austenite phase; (ii) the fraction of austenite phase is much reduced by martensite transformation during homogeneous deformation, and the grain shape keeps almost unchanged; (iii) the initial shear band is formed as transition layer, in which the grains are refined and the grain shape becomes equiaxed, along with increasing fraction of austenite phase by inverse transformation; (iv) thickening of the shear band is achieved by outward movement of the transition layers through deforming the adjoining matrix and creation of the core region through transforming the transition layers. In the core region, the fraction of austenite phase is almost disappeared and the grain size is slightly increased compared to the transition layers. So the odd micro-hardness distribution and the evolution observed in Fig. 10 are due to the competition between the variation of the austenite phase and the change of grain size in different areas.

As indicated in Fig. 3(c), the intercritical annealed $0.2 \mathrm{C} 5 \mathrm{Mn}$ TRIP steel has much higher impact shear toughness at similar dynamic shear strength level when compared to the 304 and 316L stainless steels (Xue et al., 2005; Bronkhorst et al., 2006). The high dynamic shear strength can be understood due to the ultrafine-grained austenite-ferrite duplex structure. As shown in Table 1, the fraction of austenite in the matrix is much reduced in the strong linear-hardening stage, indicating TRIP-induced hardening. However, the fraction of austenite in the matrix keeps almost unchanged afterwards, indicating that other mechanisms should operate in the plateau stage for carrying uniform plastic deformation. During the dynamic shear loading, three different phases (ferrite, austenite and martensite due to transformation) coexist in the materials. Based on stress-strain partitioning analysis by the modified law of mixture (Kuang et al., 2009), most of the strain should be carried by the austenite 
and ferrite phases, which would induce continuous austenite-to-martensite transformation, and the martensite phase should keep elastic when the fraction of martensite is very low at the front half part of the strong linear hardening stage. However, at the late part of the strong linear hardening stage and the plateau stage, the strain ratio of austenite/ferrite to martensite should become much smaller, and plastic deformation would also happen in martensite phase due to the increasing fraction of martensite phase. This increasing fraction of martensite would lead to local strain re-distribution among different phases and inhibit the transformation behaviors, as suggested in previous study (Knijf et al., 2014). Previous research also suggested that the continuous deformation with proper strain and stress partitioning among different phases based on the law of mixture can still keep a hardening potential without transformation and retard the onset of strain localization (Kuang et al., 2009; Knijf et al., 2014; Bouquerel et al., 2006; Kang et al., 2007; Jacques et al., 2007; Lani et al., 2007; Han et al., 2014; Fillafer et al., 2014; Tasan et al., 2014). Of course, this hardening potential should be much weaker than the strong hardening induced by martensite transformation. And the plateau stage may be due to the competition from this hardening potential and thermal-induced softening, and ASB is formed once this balance is broken with further deformation. Thus, the reason for the high impact toughness can be understood as twofold: (i) strong linear strain -hardening for the first stage due to TRIP effect (martensite transformation); (ii) suppressing the formation of ASB by the plateau stage due to the balance between the hardening by continuous deformation through the proper stress and strain partitioning among different phases and the adiabatic heat-induced thermal softening.

\section{Conclusions}

In the present study, the dynamic properties of the $0.2 \mathrm{C} 5 \mathrm{Mn}$ steel with ultrafine-grained austenite-ferrite duplex structure were investigated under dynamic shear loading using hat-shaped specimen set-ups in Hopkinson bar experiments. The dynamic shear process was interrupted at five different shear displacements and the microstructure was "frozen" at these stages, and then the formation and evolution mechanisms of ASB in this steel were studied using OM, SEM, EBSD, TEM and micro-hardness measurement traversing ASB. The main findings are summarized as follows:

(1) The dynamic shear response of the intercritically annealed $0.2 \mathrm{C} 5 \mathrm{Mn}$ steel after elastic deformation can be divided into three stages: (i) strong linear hardening stage; (2) plateau stage; (3) and strain softening stage associated with ASB evolution.

(2) The intercritically annealed $0.2 \mathrm{C} 5 \mathrm{Mn}$ steel was found to have much higher impact shear toughness at similar dynamic shear strength level when compared to the other steels reported in the literatures, such as 304 and 316L stainless steels (Xue et al., 2005; Bronkhorst et al., 2006). The high dynamic shear strength is due to the ultrafine-grained austenite-ferrite duplex structure. While the high impact toughness is due to the strong linear strain-hardening by martensite transformation at the first stage, and the delaying for the formation of ASB by the continuous deformation through the proper stress and strain partitioning between different phases at the plateau stage.

(3) The evolution of ASB under dynamic shear loading was found to be a two-stage process, namely an initiation stage followed by a thickening stage. The shear band consists of two regions at the thickening stages: a core region and two transition layers. The initial shear band is formed as transition layer, in which the grains are refined and the grain shape becomes equiaxed, along with increasing fraction of austenite phase by inverse transformation. In the core region, the fraction of austenite phase is almost disappeared and the grain size is slightly increased compared to the transition layers.

The results of the present paper should advance our understanding of the shear banding behaviors for the TRIP steels under extreme conditions, and provide insights for the TRIP steels in applications of energy absorbers in the automotive industry.

\section{Acknowledgments}

The work was supported by the National Key Basic Research Program of China under Grants Nos. 2012 CB932203 and 2012CB937500; National Natural Science Foundation of China under Grants Nos. 11222224, 11472286, 11072243, and 11021262. The authors would like to thank Prof. Wenquan Cao for providing the materials, and thank Dr. Husheng Zhang for helping to conduct the dynamic shear experiments.

\section{Appendix A. Supplementary data}

Supplementary data associated with this article can be found, in the online version, at http://dx.doi.org/10.1016/ j.mechmat.2015.06.004.

\section{References}

Bai, Y., Dodd, B., 1992. Adiabatic Shear Localization. Pergamon Press, New York.

Bouquerel, J., Verbeken, K., De Cooman, B.C., 2006. Microstructure-based model for the static mechanical behaviour of multiphase steels. Acta Mater. 54, 1443-1456.

Bronkhorst, C.A., Cerreta, E.K., Xue, O., Maudlin, P.J., Mason, T.A., Gray III, G.T., 2006. An experimental and numerical study of the localization behavior of tantalum and stainless steel. Int. J. Plast. 22, 1304-1335.

Chen, D., Kuo, J.C., Wu, W.T., 2011a. Effect of microscopic parameters on EBSD spatial resolution. Ultramicroscopy 111, 1488-1494.

Chen, Y.J., Li, Y.J., Walmsley, J.C., Dumoulin, S., Gireesh, S.S., Armada, S., 2011b. Quantitative analysis of grain refinement in titanium during equal channel angular pressing. Scr. Mater. 64, 904-907.

Dao, M., Lu, L., Asaro, R.J., De Hosson, J.T.M., Ma, E., 2007. Toward a quantitative understanding of mechanical behavior of nanocrystalline metals. Acta Mater. 55, 4041-4065.

Das, A., Tarafder, S., 2009. Experimental investigation on martensitic transformation and fracture morphologies of austenitic stainless steel. Int. J. Plast. 25, 2222-2247. 
Fillafer, A., Krempaszky, C., Werner, E., 2014. On strain partitioning and micro-damage behavior of dual-phase steels. Mater. Sci. Eng. A 614 180-192.

Fischer, F.D., Reisner, G., Werner, E., Tanaka, K., Cailletaud, G., Antretter, T., 2000. A new view on transformation induced plasticity (TRIP). Int. J. Plast. 16, 723-748.

Frommeyer, G., Brüx, U., Neumann, P., 2003. Supra-ductile and highstrength manganese-TRIP/TWIP steels for high energy absorption purposes. ISIJ Int. 43, 438-446.

Grässel, O., Krüger, L., Frommeyer, G., Meyer, L.W., 2000. High strength Fe-Mn-(Al, Si) TRIP/TWIP steels development-propertiesapplication. Int. J. Plast. 16, 1391-1409.

Han, H.N., Oh, C.S., Kim, G., Kwon, O., 2009. Design method for TRIP-aided multiphase steel based on a microstructure-based modelling for transformation-induced plasticity and mechanically induced martensitic transformation. Mater. Sci. Eng. A 499, 462-468.

Han, Q., Asgari, A., Hodgson, P.D., Stanford, N., 2014. Strain partitioning in dual-phase steels containing tempered martensite. Mater. Sci. Eng. A 611, 90-99.

He, B.B., Huang, M.X., Liang, Z.Y., Ngan, A.H.W., Luo, H.W., Shi, J., Cao, W.Q., Dong, H., 2013. Nanoindentation investigation on the mechanical stability of individual austenite grains in a medium-Mn transformation-induced plasticity steel. Scr. Mater. 69, 215-218.

Huang, C.X., Yang, G., Wang, C., Zhang, Z.F., Wu, S.D., 2011. Mechanical behaviors of ultrafine-grained 301 austenitic stainless steel produced by equal-channel angular pressing. Metall. Mater. Trans. A 42A, 2061 2071.

Iwamoto, T., Tsuta, T., 2000. Computational simulation of the dependence of the austenitic grain size on the deformation behavior of TRIP steels. Int. J. Plast. 16, 791-804.

Jacques, P.J., 2004. Transformation-induced plasticity for high strength formable steels. Curr. Opin. Solid St. Mater. Sci. 8, 259-265.

Jacques, P.J., Furnémont, Q., Lani, F., Pardon, T., Delannay, F., 2007. Multiscale mechanics of TRIP-assisted multiphase steels: I. Characterization and mechanical testing. Acta Mater. 55, 3681-3693.

Jia, D., Ramesh, K.T., Ma, E., 2003. Effects of nanocrystalline and ultrafine grain sizes on constitutive behavior and shear bands in iron. Acta Mater. 51, 3495-3509.

Kang, J., Ososkov, Y., Embury, J.D., Wilkinson, D.S., 2007. Digital image correlation studies for microscopic strain distribution and damage in dual phase steels. Scr. Mater. 56, 999-1002.

Knijf, D.D., Petrov, R., Fjer, C., Kestens, L.A.I., 2014. Effect of fresh martensite on the stability of retained austenite in quenching and partitioning steel. Mater. Sci. Eng. A 615, 107-115.

Kuang, S., Kang, Y.L., Yu, H., Liu, R.D., 2009. Stress-strain partitioning analysis of constituent phases in dual phase steel based on the modified law of mixture. Int. J. Min. Metall. Mater. 16, 393-398.

Lani, F., Furnémont, Q., Van Rompaey, T., Delannay, F., Jacques, P.J. Pardoen, T., 2007. Multiscale mechanics of TRIP-assisted multiphase steels: II. Micromechanical modelling. Acta Mater. 55, 3695-3705.

Lebedev, A.A., Kosarchuk, V.V., 2000. Influence of phase transformations on the mechanical properties of austenitic stainless steels. Int. J. Plast. 16, 749-767.

Lee, S., Estrin, Y., De Cooman, B.C., 2014. Effect of the strain rate on the TRIP-TWIP transition in austenitic Fe-12 pct Mn-0.6 pct C TWIP steel. Metall. Mater. Trans. A 45A, 717-730.

Luo, H.W., Shi, J., Wang, C., Cao, W.Q., Sun, X.J., Dong, H., 2011. Experimental and numerical analysis on formation of stable austenite during the intercritical annealing of $5 \mathrm{Mn}$ steel. Acta Mater. 59, 4002-4014.

Meyer, L.W., Manwaring, S., 1986. Critical adiabatic shear strength of low alloyed steel under compressive loading. In: Murr, L.E. (Ed.) Metallurgical Applications of Shock Wave and High-Strain-Rate Phenomena. Marcel Dekker, New York, pp. 657-674.

Meyers, M.A., Subhash, G., Kad, B.K., Prasad, L., 1994. Evolution of microstructure and shear-band formation in $\alpha$-hcp titanium. Mech. Mater. 17, 175-193.

Meyers, M.A., Mishra, A., Benson, D.J., 2006. Mechanical properties of nanocrystalline materials. Prog. Mater. Sci. 51, 427-556.

Miller, R.L., 1972. Ultrafine-grained microstructures and mechanical properties of alloy steels. Metall. Trans. 3, 905-912.
Mishra, A., Martin, M., Thadhani, N.N., Kad, B.K., Kenik, E.A., Meyers, M.A., 2008. High-strain-rate response of ultra-fine-grained copper. Acta Mater. 56, 2770-2783.

Niikura, M., Morris, J.W., 1980. Thermal processing of ferritic 5Mn steel for toughness at cryogenic temperatures. Metall. Trans. A 11, 15311540.

Prüger, S., Seupel, A., Kuna, M., 2014. A thermomechanically coupled material model for trip-steel. Int. J. Plast. 55, 182-197.

Pushkov, V., Yurlov, A., Bol'shakov, A., Podurets, A., Kal'manov, A., Koshatova, E., 2009. Study of adiabatic localized shear in metals by split Hopkinson pressure bar method. DYMAT: 9th International Conference on the Mechanical and Physical Behaviour of Materials Under Dynamic Loading. 395-400.

Shi, J., Sun, X.J., Wang, M.Q., Hui, W.J., Dong, H., Cao, W.Q., 2010a. Enhanced work-hardening behavior and mechanical properties in ultrafine-grained steels with large-fractioned metastable austenite. Scr. Mater. 63, 815-818.

Shi, J., Turteltaub, S., Vander Giessen, E., 2010b. Analysis of grain size effects on transformation-induced plasticity based on a discrete dislocation-transformation model. J. Mech. Phys. Solids 58, 18631878.

Somani, M.C., Juntunen, P., Karjalainen, L.P., Misra, R.D.K., Kyröläinen, A., 2009. Enhanced mechanical properties through reversion in metastable austenitic stainless steels. Metall. Mater. Trans. A 40A, 729-744.

Song, B., Chen, W., Luk, V., 2009. Impact compressive response of dry sand. Mech. Mater. 41, 777-785.

Subhash, G., Ravichandran, G., Pletka, B.J., 1997. Plastic deformation of hafnium under uniaxial compression. Metall. Mater. Trans. A 28A, 1479-1487.

Sun, J.L., Trimby, P.W., Yan, F.K., Liao, X.Z., Tao, N.R., Wang, J.T., 2014 Shear banding in commercial pure titanium deformed by dynamic compression. Acta Mater. 79, 47-58.

Sunny, G., Yuan, F.P., Lewandowski, J.J., Prakash, V., 2009. Design of inserts for split-Hopkinson pressure bar testing of low strain-to-failure materials. Exp. Mech. 49, 479-490.

Tasan, C.C., Diehl, M., Yan, D., Zambaldi, C., Shanthraj, P., Roters, F., Raabe D., 2014. Integrated experimental-simulation analysis of stress and strain partitioning in multiphase alloys. Acta Mater. 81, 386-400.

Valiev, R.Z., Langdon, T.G., 2006. Principles of equal-channel angular pressing as a processing tool for grain refinement. Prog. Mater. Sci. 51, $881-981$.

Wei, Q., Kecskes, L., Jiao, T., Hartwig, K.T., Ramesh, K.T., Ma, E., 2004 Adiabatic shear banding in ultrafine-grained Fe processed by severe plastic deformation. Acta Mater. 52, 1859-1869.

Wei, Q., Jiao, T., Ramesh, K.T., Ma, E., Kecskes, L.J., Magness, L., Dowding, R., Kazykhanov, V.U., Valiev, R.Z., 2006a. Mechanical behavior and dynamic failure of high-strength ultrafine grained tungsten under uniaxial compression. Acta Mater. 54, 77-87.

Wei, Q., Zhang, H.T., Schuster, B.E., Ramesh, K.T., Valiev, R.Z., Kecskes, L.J., Dowding, R.J., Magness, L., Cho, K., 2006b. Microstructure and mechanical properties of super-strong nanocrystalline tungsten processed by high-pressure torsion. Acta Mater. 54, 4079-4089.

Wright, T.W., 2002. The Physics and Mathematics of Adiabatic Shear Bands. Cambridge University Press, Cambridge (pp. 176-177).

Xue, Q., Gray III, G.T., Henrie, B.L., Maloy, S.A., Chen, S.R., 2005. Influence of shock prestraining on the formation of shear localization in 304 stainless steel. Metall. Mater. Trans. A 36A, 1471-1486.

Yang, Y., Jiang, F., Zhou, B.M., Li, X.M., Zheng, H.G., Zhang, O.M. 2011. Influence of shock prestraining on the formation of shear localization in 304 stainless steel. Mater. Sci. Eng. A 528, 2787-2794.

Yuan, F.P., Jiang, P., Wu, X.L., 2012. Annealing effect on the evolution of adiabatic shear band under dynamic shear loading in ultra-finegrained iron. Int. J. Impact Eng. 50, 1-8.

Zaera, R., Rodríguez-Martínez, J.A., Vadillo, G., Fernández-Sáez, J., 2014. Dynamic necking in materials with strain induced martensitic transformation. J. Mech. Phys. Solids 64, 316-337.

Zhilyaev, A.P., Langdon, T.G., 2008. Using high-pressure torsion for metal processing: fundamentals and applications. Prog. Mater. Sci. 53, 893 979. 